\title{
A Study on Knowledge Hiding: Visualized Quantitative Analysis Based on Note Express
}

\author{
Fan Yang ${ }^{1,2, a}$, Long Yang ${ }^{3 *}$ \\ ${ }^{1}$ Social Science Office, School of Tourism and Cultural Industry, Chengdu University, Chengdu, China \\ ${ }^{2}$ College of Management Science, Chengdu University of Technology, Chengdu, China \\ ${ }^{3}$ Business School, Chengdu University, Chengdu, China \\ ayangfan@cdu.edu.cn \\ *Corresponding author. Email: yanglong@cdu.edu.cn
}

\begin{abstract}
Knowledge hiding refers to the deliberate hiding of individuals in an organization in the face of their colleagues' knowledge requests. At present, the research review in this field is mainly based on the qualitative research method, relying on the author's subjective intention to build the theoretical framework, lack of quantitative objective analysis. Taking the literatures on knowledge hiding research in Web of Science database and CNKI database as the research object, this paper used the visualization software Note Express to sort out the dimensions of the research on knowledge hiding, such as the annual distribution, literature type and source distribution, author quantitative analysis, title (participle) quantitative analysis and keyword quantitative analysis. The basic status of knowledge hiding research is summarized. By analyzing the research contents of knowledge hiding, we extracted four themes, the concept and classification of knowledge hiding, theoretical support, research methods and research perspectives, and clarified the evolutionary context of knowledge hiding research. The future research direction is put forward.
\end{abstract}

Keywords: Knowledge hiding, Note Express, Quantitative analysis

\section{INTRODUCTION}

After graduating from graduate school, Xiao Li came to a new job. He is mainly responsible for the maintenance and management of customer relationship data. Recently, he encountered a problem. In the process of sorting out customer relationship data, he found that part of the data in the system was missing. So he asked an old employee who had done this work before for guidance. But the old employee said he did not know the reason and did not know how to deal with it, and led him to ask others for help. Old employees may be reluctant to tell Xiao Li from the perspective of his occupational safety, but also may not want to tell Xiao Li because of the tight working time. In this case, when faced with Xiao Li's request for knowledge, the old employee's behavior of deliberately hiding called knowledge hiding [1]. In daily work, in order to improve organizational performance, organizations and leaders will try every means to encourage employees to share knowledge and avoid unreasonable knowledge hiding. But many times it doesn't work. The reasons are as follows: on the one hand, knowledge hiding is not easy to be found and difficult to define; On the other hand, knowledge sharing is difficult to quantify and motivate. Therefore, this study shifts the perspective from knowledge sharing to knowledge hiding. Based on the visualization software of Note Express, the research literatures on knowledge hiding in the Web of Science database and the CNKI database were summarized by taking 1977-2021 as the time window. We hope to reveal the development process of knowledge hiding research, and to explore the precursor guiding factors, operational mechanism and result performance of knowledge hiding. The research results will provide important reference for organizational knowledge management practice.

\section{DATA SOURCES AND RESEARCH METHODS}

In the Web of Science database (retrieved on January 22,2021 ), a total of 232 relevant literatures were obtained by searching with title= "knowledge hiding". In the CNKI database (retrieved on January 22, 2021), we searched under the title = "knowledge hiding", and obtained a total of 553 relevant literatures. Note Express software was 
used to check repetitions, 210 duplicate literatures were eliminated, and 575 valid literatures were finally obtained. Then, the annual number of published articles, the literature source word frequency cloud map, the author word frequency statistics, the title (participle) count and the keyword word frequency statistics were obtained from 575 literatures. Finally, quantitative data and visual maps are generated, and we draw conclusions by classifying them.

\section{QUANTITATIVE ANALYSIS OF KNOWLEDGE HIDING}

\subsection{Annual number of literatures published}

In 1977, Hamburger, J. began to study knowledge hiding from the perspective of imperfect chemical terms. The period from 1997 to 2001 was the initial stage of knowledge hiding research, and the research results were few. The period from 2002 to 2013 was the middle stage of knowledge hiding research. The number of published literatures increased, and knowledge hiding gradually attracted the attention of scholars. In 2012, Connely discovered people's knowledge hiding behavior at work, and elaborated the difference and connection between knowledge hiding, knowledge sharing and knowledge hoarding[1].The period from 2014 to 2021 is a hot stage of knowledge hiding research, and the number of published literatures has increased significantly. On the whole, the concept of knowledge hiding is expanded, and the whole study reflects the transition from explicit knowledge hiding to tacit knowledge hiding. The details are shown in Figure 1.

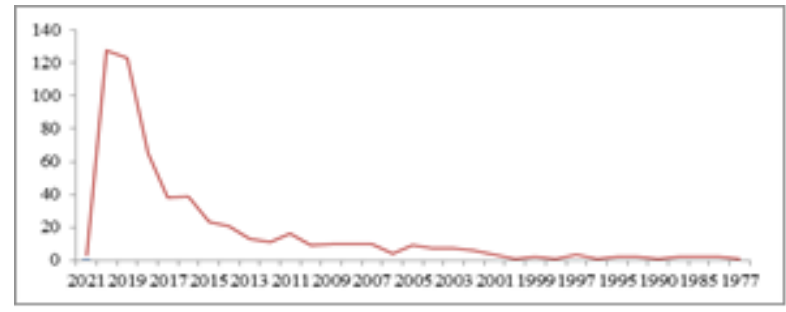

Figure 1 Trend chart of annual number of articles published

\subsection{Literature types and sources}

From the perspective of literature types, in the studies whose titles are knowledge hiding, Journal articles account for $94.09 \%$, Thesis $5.22 \%$, book $0.35 \%$ and book Section $0.35 \%$. The details are shown in Figure 2.

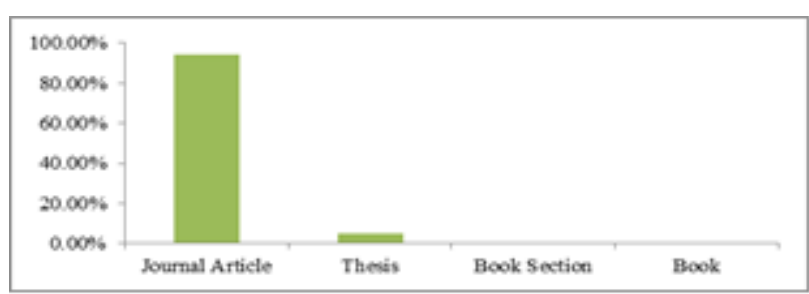

Figure 2 Literature types
In terms of Journal sources, among foreign journals, researches related to knowledge hiding are published in the Journal of Knowledge Management (SSCI), Science Letter, Journal of Engineering, Journal of Robotics \& Machine Learning, Computer Technology Journal, Ecology Environment \& Conservation, Computers, Networks \& Communications, and so on. In Chinese journals, researches on knowledge hiding have been published on the Science \& Technology Progress and Policy (CSSCI), Science and Technology Management Research, Science Research Management (CSSCI), Soft Science (CSSCI), East China Economic Management, Human Resources Development of China, Information Studies: Theory \& Application (CSSCI), and so on. The details are shown in Figure 3.

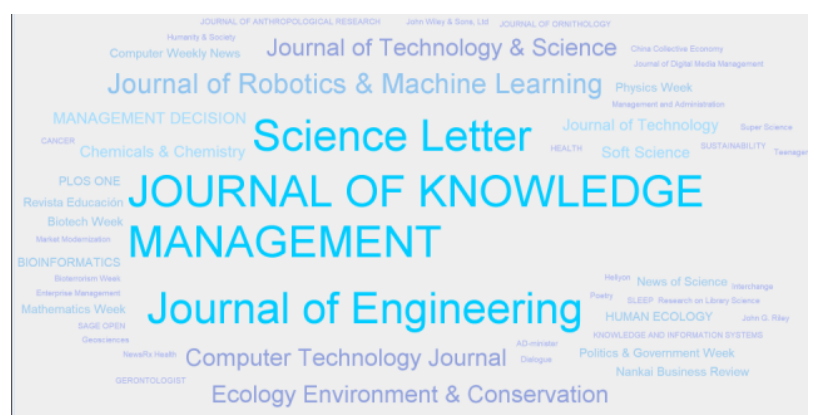

Figure 3 Journal source word frequency cloud map

\subsection{Quantitative analysis of authors}

Note Express software was used to conduct statistics on the authors of literatures related to knowledge hiding, and a total of 1210 authors were found in 575 literatures. According to Price law, authors whose number of publications $\geq \mathrm{m}=0.749 * \sqrt{\mathrm{N}_{\max }}$ are considered core authors. The number of literatures published by a single author related to knowledge hiding is $\mathrm{N}_{\max }=8$, so the authors with 3 or more literatures published are the core authors in this field. According to the statistics of authors' publishing frequency, there are 40 core authors, accounting for $3.3 \%$ of the total number of authors. The total number of literatures published by the core authors was 164 , accounting for $11.5 \%$ of the total number of literatures published. The statistics of authors who published more than 4 papers are shown in Figure 4. These statistical results are quite different from Price law that half of the literatures are written by core authors, and the number of core authors is approximately equal to the square root of the total number of authors. The results show that the core authors of knowledge hiding research have not formed an effective group [2]. 


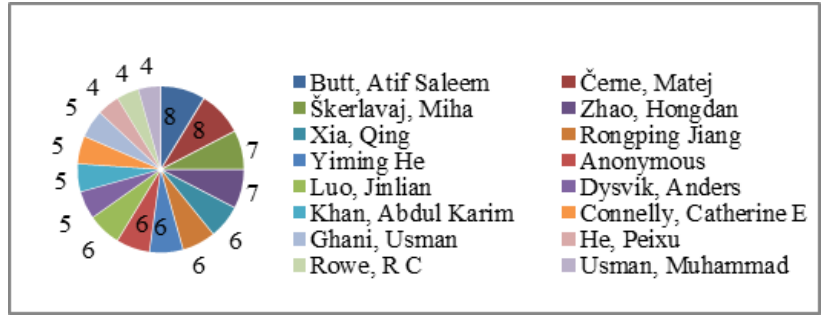

Figure 4 Statistics on the number of literatures published by authors with more than 4

\subsection{Title (participle) quantitative analysis}

The most frequent of title (participle) is knowledge hiding. The influencing factors of knowledge hiding, behavioral representation, management research and knowledge mining account for a large proportion. At present, the research on the relationship and mechanism between workplace, technical tools, leaders, social relations and knowledge hiding is the mainstream in universities, enterprises, teams and other organizations. Empirical studies examine the mediating variable effect on knowledge hiding behavior, and the moderating variable effect is favored by scholars. Table 1 describes the partial title (participle) distribution.

Table 1. Title (Participle) Frequency Statistics (Incomplete)

\begin{tabular}{|c|c|c|c|c|c|}
\hline NO. & Title (participle) & Frequency & NO. & $\begin{array}{c}\text { Title } \\
\text { (participle) }\end{array}$ & Frequency \\
\hline 1 & Knowledge & $22.92 \%$ & 20 & Mining & $0.80 \%$ \\
\hline 2 & $\begin{array}{l}\text { Hiding/ } \\
\text { Hidden }\end{array}$ & $\begin{array}{l}11.31 \% / \\
10.58 \%\end{array}$ & 21 & Workplace & $0.80 \%$ \\
\hline 3 & University & $3.86 \%$ & 22 & Physics & $0.69 \%$ \\
\hline 4 & Data & $3.32 \%$ & 23 & Sharing & $0.69 \%$ \\
\hline 5 & Behavior & $2.9 \%$ & 24 & Consequences & $0.61 \%$ \\
\hline 6 & Impact & $1.95 \%$ & 25 & Ecology & $0.57 \%$ \\
\hline 7 & Information & $1.83 \%$ & 26 & Human & $0.57 \%$ \\
\hline 8 & Science & $1.76 \%$ & 27 & Moderating & $0.57 \%$ \\
\hline 9 & Technology & $1.64 \%$ & 28 & Mechanism & $0.57 \%$ \\
\hline 10 & Advance & $1.49 \%$ & 29 & Antecedents & $0.46 \%$ \\
\hline 11 & $\begin{array}{l}\text { Findings/ } \\
\text { Discovery }\end{array}$ & $\begin{array}{l}1.45 \% / \\
0.50 \%\end{array}$ & 30 & Networks & $0.46 \%$ \\
\hline 12 & Role & $1.30 \%$ & 31 & Relationship & $0.96 \%$ \\
\hline 13 & Model & $1.15 \%$ & 32 & Systems & $0.46 \%$ \\
\hline 14 & Employees & $1.15 \%$ & 33 & Leadership & $0.46 \%$ \\
\hline 15 & Organization & $1.14 \%$ & 34 & Intelligence & $0.42 \%$ \\
\hline 16 & Effect & $1.03 \%$ & 35 & Learning & $0.42 \%$ \\
\hline 17 & Social & $0.92 \%$ & 36 & Perspective & $0.42 \%$ \\
\hline 18 & Engineering & $0.80 \%$ & 37 & Project & $0.42 \%$ \\
\hline 19 & Management & $0.80 \%$ & 38 & & \\
\hline
\end{tabular}

\subsection{Keywords quantitative analysis}

Figure 5 is drawn according to keyword frequency statistics. Psychological ownership theory, work characteristics theory, grounded theory, social exchange theory and Machiavellianism have become the main theoretical bases of knowledge hiding research. Organizational level, leadership level and individual level constitute the hierarchical structure of knowledge hiding research. Organizational support, leadership style and personal traits are the important influencing factors of knowledge hiding behavior. 


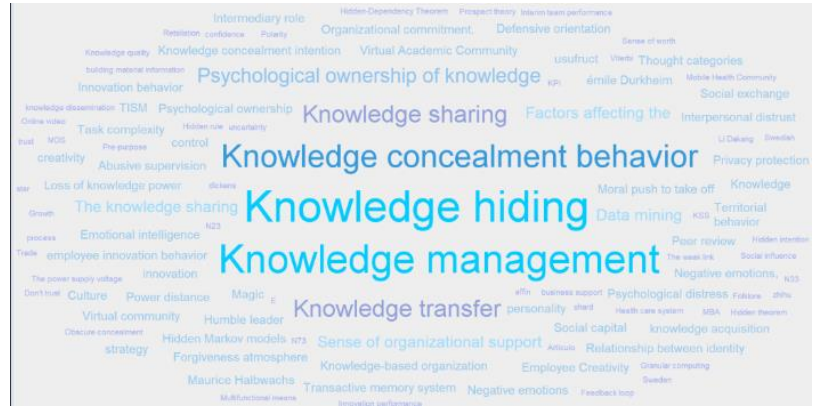

Figure 5 Cloud diagram of keyword frequency

\section{QUANTITATIVE ANALYSIS OF KNOWLEDGE HIDING RESEARCH CONTENT}

\subsection{Knowledge hiding concepts and categories}

Connely believes that knowledge hiding and knowledge sharing are two completely different concepts. He divided knowledge hiding into deceptive knowledge hiding, evasive knowledge hiding and rational knowledge hiding. Deceptive knowledge hiding refers to refusing to provide knowledge on the ground of pretending not to know when being asked. Evasive knowledge hiding refers to providing partial knowledge when being asked. Reasonable knowledge hiding refers to refusing to provide knowledge for reasonable reasons [1]. On this basis, Jha, J. K. and Varkkey, B. (2018) put forward the rhetorical knowledge hiding, which refers to refusing to provide knowledge in the form of rhetorical questions when being asked [3]. Xiao M. and Fang L. C. further elaborated the differences and connections between knowledge retention, knowledge hoarding, employee silence and knowledge hiding [4].

\subsection{Supporting theoretical research}

Based on the theory of social exchange and the theory of resource conservation, we examine the mechanism of organizational psychological ownership on knowledge hiding, including the mediating effect of organizational citizenship behavior and citizen fatigue, and the moderating effect of transformational leadership[5][6]. Knowledge hiding behavior was studied from the perspective of leader-member exchange theory [7]. Based on social exchange theory and social cognition theory, it is proposed that non-superior-subordinate relationship has an impact on employees' knowledge hiding behavior through psychological security [8]. The resource protection theory is used to explain that employees are more likely to have knowledge hiding behavior when they experience high time pressure [9]. Based on the theory of achievement goal and the theory of job characteristics, this paper explores the multi-level interaction between team, job relevance and individual characteristics in motivating employees' innovative work behavior [10]. Based on the group involvement model of social identity theory, this paper explores how procedural justice affects employees' knowledge hiding behavior [11].

\subsection{Main research methods}

A case study using structured interview method is conducted to explore the relationship between managers' personal traits and knowledge hiding in supply chain cooperative enterprises [12] and the reasons for knowledge hiding among managers of supply chain enterprises [13][14]. Empirical research method is used to examine the mechanism of knowledge hiding behavior [15][16][17] Review and prospect the research vein of knowledge hiding by using literature research method [4][18]. The consistency and stability of the research results of the same object at different time stages are tested by using the time-delay method [19][20]. The comparative research method is used to verify the causes of knowledge hiding behavior of different research objects [21].

\subsection{Main research perspectives}

At present, knowledge hiding is mainly studied from the following perspectives: Knowledge hiding behavior of superior and subordinate in the organization [8][22] [23][24]. The relationship between leadership style, organizational management and knowledge hiding [25][26][27]. The relationship between knowledge hiding and innovation [28][29]. Knowledge hiding results performance [30]. Data mining technology of privacy knowledge [31][32] and hiding algorithm improvement [33][34]. Antecedents and intervention mechanisms of knowledge hiding behavior of R\&D team members [35]. Analysis of individual knowledge hiding behavior and knowledge hiding intention [36][37].The relationship between individual traits and knowledge hiding [15][38].

\section{CONCLUSION}

Knowledge hiding behavior is difficult to detect and define. Based on the existing research, it is of great significance and value to strengthen the innovative research on the concept extension, classification and measurement of knowledge hiding. At present, management and psychology theories are mainly used as the theoretical basis of knowledge hiding research. The perspective of theoretical research can be broadened in the future. Knowledge hiding behavior is the result of the game between individuals, so we can try to use the game theory to study knowledge hiding in the future. Most of the research reviews in the field of knowledge hiding are mainly based on qualitative research methods, which rely on the author's subjective intention to build a theoretical framework, and lack of quantitative objective analysis [39]. This paper uses quantitative analysis method to 
review the existing research results, the research method is more scientific. In the future, the scope of the database can be expanded to enhance the systematic and comprehensive of the research. There are many researches on knowledge hiding behavior in enterprises and organizations, but few involving research teams and online communities [40]. In the era of big data, virtual community is replacing the traditional organizational form into social production and life. It is of great practical significance to broaden the research perspective and study the knowledge hiding behavior of virtual community. Some of the current research results still have the problem of insufficient stability. In the future, it is necessary to expand the sample body scope and increase the sample size to further discuss the reasons for insufficient stability.

\section{FUNDING}

This work was supported by the Education Department Project of Sichuan under Grant DM201721.

\section{AUTHORS' CONTRIBUTIONS}

Fan Yang established the framework of the paper, wrote the first draft, and finalize the final draft. Long Yang uses software to make statistics.

\section{ACKNOWLEDGMENTS}

We are extremely grateful to the anonymous reviewers who provided helpful comments and suggestions to significantly improve the quality of our paper.

\section{REFERENCES}

[1] Connelly, C. E. (2012) Knowledge hiding in organizations. Journal of Organizational Behavior, 33:64-88.

[2] Zheng, C., Li, Y. (2020) Research Status of Archives Management in the Context of Cloud Computing -- Qualitative Analysis Based on Note Express. Inside and Outside Lantai,19: 25-27.

[3] Jha, J. K., Varkkey, B. (2018) Are you a cistern or a channel? Exploring factors triggering knowledge hiding behavior at the workplace: vidence from the Indian R\&D professionals. Journal of Knowledge Management, 22:824-849.

[4] Xiao, M., Cooke, F. L.(2019) Why and when knowledge hiding in the workplace is harmful: a review of the literature and directions for future research in the Chinese context. Asia Pacific Journal of Human Resources, 57:470-502.

[5] Jiang, R., He, Y. (2020) How does organizational psychological ownership affect knowledge hiding behavior: The role of citizen fatigue and transformational leadership. Science \& Technology Progress and Policy, 37:116-124.

[6] Ghani, U. et al. (2020) Tit for Tat: Abusive Supervision and Knowledge Hiding--The Role of Psychological Contract Breach and Psychological Ownership. International Journal of Environmental Research and Public Health, 17: 1240.

[7] Babič K. et al. (2019) Are we in this together? Knowledge hiding in teams, collective prosocial motivation and leader-member exchange. Journal of Knowledge Management, 23:1502-1522.

[8] He, P. et al. (2020) Linking work-related and nonwork-related supervisor-subordinate relationships to knowledge hiding: a psychological safety lens. Asian Business \& Management.

[9] škerlavaj M. et al. (2018) Tell me if you can: time pressure, prosocial motivation, perspective taking, and knowledge hiding. Journal of Knowledge Management, 22:1489-1509.

[10] černe M. et al. (2017) The role of multilevel synergistic interplay among team mastery climate, knowledge hiding, and job characteristics in stimulating innovative work behaviour. Human Resource Management Journal, 27: 281-299.

[11] Zhao H., Zhou X. (2020) Perceived procedural justice and employee knowledge hiidng: A perspective from the group involvement model. Shanghai Management Science, 42:91-99.

[12] Butt A. S. (2020) Mitigating knowledge hiding in a buyer - supplier relationship: An exploratory study. Knowledge and Process Management, 27:187-196.

[13] Butt A. S. et al. (2020) Knowledge Hiding in a Buyer-Supplier Relationship: Present and Future Scope. International Journal of Knowledge Management, 16:18-29.

[14] Butt A. S. (2019) Antecedents of knowledge hiding in a buyer-supplier relationship. Knowledge and Process Management, 26.

[15] Hernaus T. et al. (2019) Evasive knowledge hiding in academia: when competitive individuals are asked to collaborate. Journal of Knowledge Management, 23:597-618.

[16] He, Y., Jiang, R. (2016) The relationship between uncertainty of human capital property right and knowledge hiding in Internet industry. Social Sciences in Guangdong, 02: 20-28.

[17] Jiang, R., He, Y. (2014) The influence mechanism of psychological ownership of knowledge on knowledge hiding: An empirical study based on 
intellectual organizations. Science \& Technology Progress and Policy, 31:128-133.

[18] He, Y., Jiang, R. (2014) Knowledge hiding behavior in organizations: review and prospect. Human Resources Development of China, 13:49-55.

[19] Zhao, H. et al. (2019) Leader-member exchange, organizational identification, and knowledge hiding: The moderating role of relative leader-member exchange. Journal of Organizational Behavior, 40: 834-848.

[20] Zhao, H. et al. (2016) Workplace ostracism and knowledge hiding in service organizations. International Journal of Hospitality Management, 59:84-94.

[21] Zhao, H., Xia, Q. (2019) Nurses' negative affective states, moral disengagement, and knowledge hiding: The moderating role of ethical leadership. Journal of Nursing Management, 2:357-370.

[22] Butt A. S. (2019) Consequences of top-down knowledge hiding in firms: A pilot study. Heliyon, 5:e03000-e03000.

[23] Butt A. S. (2020) Business--Asian Business Management: Data from America University Ras Al Khaimah Provide New Insights into Asian Business Management. Journal of Engineering, 2020.

[24] Butt A. S., Ahmad, A. B. (2019) Are there any antecedents of top-down knowledge hiding in firms? Evidence from the United Arab Emirates. Journal of Knowledge Management, 23:1605-1627.

[25] Men, C. et al. (2020) Ethical Leadership and Knowledge Hiding: A Moderated Mediation Model of Psychological Safety and Mastery Climate. Journal of Business Ethics, 166:461-472.

[26] Yuan, L. Zhang, L, Tu Y. (2018) Study on the relationship between humble leadership and employee knowledge hiding curve. Soft Science, 32: 86-88.

[27] Khalid, M. et al. (2018) When and how abusive supervision leads to knowledge hiding behaviors. Leadership \& Organization Development Journal, 39: 794-806.

[28] Fong, P. S. W. et al. (2018) Knowledge hiding and team creativity: the contingent role of task interdependence. Management Decision, 56: 329343.

[29] černe M. et al. (2014) What Goes Around Comes Around: Knowledge Hiding, Perceived Motivational Climate, And Creativity. The Academy of Management Journal, 57:172-192.
[30] Connelly, C. E., Zweig, D. (2015) How perpetrators and targets construe knowledge hiding in organizations. European Journal of Work and Organizational Psychology, 24:479-489.

[31] Vassilios S. V. (2013) Association rule hiding methods. Wiley Interdisciplinary Reviews: Data Mining and Knowledge Discovery, 3:28-36.

[32] Gkoulalas-Divanis, A., Verykios, V. S. (2009) Hiding sensitive knowledge without side effects. Knowledge and Information Systems, 20: 263-299.

[33] Gkoulalas-Divanis, A., Verykios, V. S. (2009) Exact Knowledge Hiding In Transactional Databases. International Journal on Artificial Intelligence Tools, 18:17-37.

[34] George, V. M., Vassilios S. V. (2008) A MaxMin approach for hiding frequent itemsets. Data \& Knowledge Engineering, vol. 65: 75-89, 2008.

[35] Huo, W. et al. (2016) Antecedents and intervention mechanisms: a multi-level study of R\&D team's knowledge hiding behaviour. Journal of Knowledge Management, 20:880-89.

[36] Zhang, M., Luo, H., Nie, R. (2017) Analysis on the hidden intention of tacit knowledge of individual members of university scientific research team. Journal Of Knowledge Management, 40:880-897.

[37] Zhang, M., Ma, Z. Zhang, Y. (2018) The formation path of users' subjective knowledge hiding behavior in online health communities. Information Studies: Theory \& Application, 41:111-117.

[38] Shahid I. M. et al. (2020) Personality traits predicting knowledge hiding behaviour: Empirical evidence from academic institutions of Pakistan. Business Information Review, 37.

[39] Zhao, H. Liu, W. (2020) Knowledge hiding: A review of research based on knowledge graph. Foreign Economics \& Management, 42:121-138.

[40] Zhang, M., Ma, Z., Zhang, Yan. (2018) A review of user knowledge hiding: analysis of research contents, knowledge systems and leading topics. Research on Library Science, 14:2-9. 